\title{
Retrograde Removal of broken Intra Medullary Femoral Nail An Innovative Technique
}

\author{
Syed Arsalan Haider Bukhari* \\ A.M. College, Pakistan \\ Submission: October 02, 2017; Published: October 16, 2017 \\ *Corresponding author: Syed Arsalan Haider Bukhari, Associate professor A.M. College and HOD, Pakistan, Tel: 03219846476, \\ Email: bonemender541@gmail.com
}

\begin{abstract}
Objective: Intra medullary nailing of long bones is a standard procedure in most of the orthopedic Centers all around the globe. Breakage of these nails for one reason or the other poses a dilemma for the operating surgeon especially if specialized instrumentation is not available for removal of the broken nail fragments. Extraction of the distal end of these broken segments of intra medullary nails forms the main part of this operative challenge. We report a retrospective case series where a simple technique of retrograde extraction of broken femoral nail utilizing a specially made $5 \mathrm{~mm}$ ball-tipped guide wire was applied. This best thing about this method was that it did not require any additional sophisticated expensive instrumentation to get the desire outcome.
\end{abstract}

Study design: Cross sectional retrospective study.

Methodology: Six patients ( 5 males: 1 female) with diaphyseal fractures of femur treated with intra medullary nailing were included in this study who presented to orthopedic department of CMH Multan between Sept 2014 to Jan 2015 with complaints of broken femoral intra medullary nails. All these patients underwent the same method of broken nail extraction and results were evaluated in terms of ease of removal, intra procedural difficulties like fragment impaction, wire breakage and efficacy of ball tip hold on the broken nail fragment lodged in the distal fracture fragment. In this technique a standard $5 \mathrm{~mm}$ tipped guide wire was passed retrograde to remove the broken nail out of the proximal wound.

Results: Utilizing this method in all the patients included in this study it was found that removal of the problematic distal fragment of the broken annulated intra medullary nail was quite easy without any intra operative glitches. No post-operative complications were encountered also. Above all the integrity of the knee was maintained as no formal arthrotomy was carried out. All patients then underwent exchange nailing with a larger diameter intra medullary nail. None of the patients had any complaints at the knee joint when they reported for their femur fracture follow up in orthopedic OPD.

Conclusion: Although the number of patients in our study was small but based on the factors like consistence of ease and successful outcomes in employing this technique, we conclude that this technique is an extremely user friendly technique for successful extraction of the broken intra medullary femoral nails; especially the distal fragment of broken nail, without causing any additional trauma to patient which is usually seen when additional surgical approaches are used to remove such broken intra-medullary nails.

Keywords: fractures, femur, broken intra medullary nail, extraction, Ball-tipped guide wire

\section{Introduction}

Diaphyseal fractures of femur are a common injury in orthopedic practice. The use of intra medullary nails for management of such fractures is a universally accepted technique. Besides the remarkable advantages of this procedure, the underside remains the fact that when these nails can break due to fracture nonunion, poor quality of implant or trauma. The intra medullary placement of these implants makes their extraction for exchange nailing a difficult task requiring a substantial amount of effort and an added tissue trauma. Numerous techniques have evolved with time for extraction of the broken intra medullary nail especially its distal part which is in fact the most difficult to retrieve and usually requires expensive and special extraction equipment. At many centers such equipment may not be available making this procedure a very difficult and tedious process. In addition significant tissue trauma is also incurred in many such procedures thereby causing intra-operative complications and / or affecting the postoperative outcomes [1-4]. We thereby practiced a very simple method of extraction of the distal broken annulated femoral nail fragment in six patients by utilizing a $5 \mathrm{~mm}$ ball-tipped guide wire and a $6 \mathrm{~mm}$ annulated drill bit readily available in an orthopedic setup and noted the outcomes against pre decided criterions. 


\section{Materials and Methods}

A retrospective study involving six patients was carried out at CMH Multan orthopedic unit where they presented with broken femoral intra medullary nail. In two patients 24 years /43 years) the nail broke due to fracture nonunion and in one case (aged 23 years) the size of nail was less $(9 \mathrm{~mm})$ as compared to standard instructions ( $12 \mathrm{~mm}$ onwards). In two patients (32 yr. / 38yr) the quality of the nail was very poor and in one of the cases it appeared as a reused nail. In one patient (F / 21 yr.) the nail was broken due to re trauma of fall. The average time of presentation after the breaking of nail was 2 weeks. In order to manage these cases involving the removal of the broken nail segments and exchange nailing we applied a novel technique [5].

In this technique after removal of the screws and broken proximal nail fragment, the knee was flexed to 40 degrees and a stab incision made in the infra patellar area. A guide wire was then passed through it into the intercondylar region of the knee under image intensifier guidance. Over this wire a 6 -millimeter annulated drill bit was used to drill a hole through the bone. Then a $5 \mathrm{~mm}$ ball tipped guide wire was eased through it in a retrograde manner into the distal fragment of the broken nail and finally was passed out through the supra trochanteric / gluteal wound. The intra medullary area of the femur was then reamed to $2 \mathrm{~mm}$ size above the nail size and then the broken distal fragment of the nail was removed with gentle thumps in retrograde manner till it was extracted. The distal fragment of the femur was then reamed to the same size as the proximal fragment and finally new nail inserted over a guide wire and interlocked [6,7].

\section{Results}

The technique was successfully used in six patients (Table 1) between Sept 2014 to April 2015 all patients had femur diaphyseal fractures treated with intra medullary nailing. The common site of nail breakage was just distal to the femur isthmic region (4 cases) One patient had nail breakage at proximal of the distal two holes and one at the middle (post trauma). All the patients with broken nails underwent successful nail extraction by the above mentioned technique and closed exchange reamed nailing with a larger nail was done with satisfactory outcomes. The average operating time for exchange revision was 60 min (range 45-65 $\mathrm{min}$ ) and the mean time for successful bony union seen radio logically was five months (range 4-6 months). In terms of ease of removal the procedure was systematic and easy, no major intra procedural difficulties like fragment impaction or wire breakage were encountered. The efficacy of ball tip to hold on the broken nail fragment lodged in the distal fracture fragment was found to be excellent. None of the patients had any functional disability at the knee joint. The average Tegner Lysol Knee Score was 90 (85-95). The best part of this technique was that the opening of the knee joint just required a stab percutaneous incision no larger than the one made for an arthroscopic entry. In addition the articular cartilage was breached in the intracondylar area well away from the weight-bearing surfaces. Keeping the knee flexed to 40 degrees prevented any injury to the cruciates and allowed easy egress to the wire. None of the patient had nay post-operative knee stiffness and were ambulant with frame as early as 4 th post op day [8-12].

Table 1

\begin{tabular}{|c|c|c|c|c|}
\hline Sno & Sex & $\begin{array}{l}\text { Site of nail } \\
\text { breakage }\end{array}$ & $\begin{array}{l}\text { Operating } \\
\text { time }\end{array}$ & $\begin{array}{c}\text { Tagner } \\
\text { lysholm knee } \\
\text { score }\end{array}$ \\
\hline 1 & Male & $\begin{array}{l}\text { Above Isthmus of } \\
\text { diaphysis femur }\end{array}$ & $45 \mathrm{~min}$ & 85 \\
\hline 2 & Female & Middle of nail & $65 \mathrm{~min}$ & 90 \\
\hline 3 & Female & $\begin{array}{l}\text { Above Isthmus of } \\
\text { diaphysis femur }\end{array}$ & $65 \mathrm{~min}$ & 95 \\
\hline 4 & Male & $\begin{array}{l}\text { Above Isthmus of } \\
\text { diaphysis femur }\end{array}$ & $65 \mathrm{~min}$ & 90 \\
\hline 5 & Male & Lower end of nail & $65 \mathrm{~min}$ & 85 \\
\hline 6 & Male & $\begin{array}{l}\text { Above Isthmus of } \\
\text { diaphysis femur }\end{array}$ & $55 \mathrm{~min}$ & 95 \\
\hline
\end{tabular}

\section{Discussion}

Broken intra medullary nail is a major challenge to an orthopedic surgeon who does not want to open up the fracture to extract it especially in face of osteoporotic bones. A variety of techniques and their variations have been used to extract the broken implant by closed technique from the long bones. The method applied to achieve this goal in our study is simple and does not entail any special surgical paraphernalia or instrumentations than the one in common use in daily practice of orthopedic trauma operating suite. The surgical incision is the same as that which would be used for the purpose of exchange nailing that follows the removal of the broken nails in most cases. The mainstay of our technique is that the nail is extracted through the proximal wound and this does not cause any damage to the sensitive cruciate ligaments of the knee. Moreover, avoidance of extraction of broken distal end of the nail also does not cause any damage to the articular cartilage. These factors successfully prevent any disability from the knee intervention $[13,14]$. Many publications about ante grade extraction of broken femoral nails through the knee joint, on the contrary, have shown damage to knee with early onset of osteoarthritis changes or painful knee. In few reported cases ACL/ PCL injury has been reported also where the nail exited through the knee joint [15]. Our technique is a simple and easily reproducible substitute that does not disturb the bone healing site, knee joint surface and is can easily be executed through a small knee infra-patellar arthrotomy [16].

\section{References}

1. Franklin JL, Winquist RA, Benirschke SK, Hansen ST Jr (1988) Broken intra medullary nails. J Bone Joint Surg Am 70(10): 1463-1471.

2. Brewster NT, Ashcroft GP, Scotland TR (1995) Extraction of broken intra medullary nails an improvement in technique. Injury 26(4): 286.

3. Sreenivasulu Metikala, Riazuddin Mohammed (2011) Closed retrograde retrieval of the distal broken segment of femoral cannulated 
intramedullary nail using a ball-tipped guide wire. Indian J Orthop 45(4): 347-350.

4. Levy O, Amit Y, Velkes S, Horoszowski H (1994) A simple method for removal of a fractured intramedullary nail. J Bone Joint Surg Br 76: 502-503.

5. Charnley GJ, Farrington WJ (1998) Laparoscopic forceps removal of a broken tibial intramedullary nail. Injury 29(6): 489-90.

6. Marwan M, Ibrahim M (1999) Simple method for retrieval of distal segment of the broken interlocking intramedullary nail. Injury 30(5): 333-335.

7. Khan FA (1992) Retrieval of a broken intramedullary femoral nail. Injury 23(2): 129-130.

8. Magu NK, Sharma AK, Singh R (2004) Extraction of the broken intramedullary femoral nail an innovative technique. Injury 35(12): 1322-1323.

9. Middleton RG, McNab IS, Hashemi Nejad A, Noordeen MH (1995) multiple guide wire technique for removal of the short distal fragment of a fractured intramedullary nail. Injury 26(8): 531-532.
10. Park SY, Yang KH, Yoo JH (2006) Removal of a broken intramedullary nail with a narrow hollow. J Orthop Trauma 20(7): 492-494

11. Maini, Upadhyay A, Aggarwal A, Dhaon BK (2002) A new method of removing a fractured interlocked nail. Injury 33(3): 261-262.

12. Georgilas I, Mouzopoulos G, Neila C, Morakis E, Tzurbakis M (2009) Removal of broken distal intramedullary nail with a simple method: a case report. Arch Orthop Trauma Surg 129(2): 203-205.

13. Maheshwari R, Tadross TS (2006) Extracting broken intramedullary femoral nails. Orthopedics 29(10): 880-881.

14. Karladani AH (2006) Removal of a broken nail using a guide wire and a screw. Acta Orthop 77(6): 986-988.

15. Sivananthan KS, Raveendran K, Kumar T, Sivananthan S (2000) A simple method for removal of a broken intramedullary nail. Injury 31(6): 433-434.

16. de Amorim Cabrita HA, Malavolta EA, Teixeira OV, Montenegro NB, Duarte FA, et al. (2010) Anterograde removal of broken femoral nails without opening the nonunion site: a new technique. Clinics (Sao Paulo) 65(3): 279-283.

\section{Your next submission with Juniper Publishers will reach you the below assets}

- Quality Editorial service

- Swift Peer Review

- Reprints availability

- E-prints Service

- Manuscript Podcast for convenient understanding

- Global attainment for your research

- Manuscript accessibility in different formats

( Pdf, E-pub, Full Text, Audio)

- Unceasing customer service

Track the below URL for one-step submission https://juniperpublishers.com/online-submission.php 